\title{
Ophthalmic Suspension Dosage Form
}

National Cancer Institute

\section{Source}

National Cancer Institute. Ophthalmic Suspension Dosage Form. NCI Thesaurus. Code C91164.

A suspension intended for administration in or around the eye. 